\title{
Effect of age on production characteristics of Boschveld indigenous chickens of South Africa reared intensively
}

\author{
V.M.O. Okoro ${ }^{\# 1}$, K.E. Ravhuhali ${ }^{2}$, T.H. Mapholi ${ }^{3}$, E.F. Mbajiorgu ${ }^{4}$ \& C.A. Mbajiorgu ${ }^{1}$ \\ ${ }^{1}$ Department of Agriculture and Animal Health, University of South Africa, Florida Science Campus, Florida. \\ ${ }^{2}$ Department of Animal Science, School of Agricultural Sciences, Faculty of Agriculture, Science and Technology, North- \\ West University, Mmabatho, Mafikeng 2735, South Africa \\ ${ }^{3}$ Department of Agriculture, Land Reform, Bela-Bela Municipality, Waterberg District, Limpopo Province, P/bag x1676, \\ Bela-Bela, 0480 South Africa \\ ${ }^{4}$ Faculty of Health Sciences, School of Anatomical Sciences, University of the Witwatersrand, South Africa
}

(Received 26 August 2016; Accepted 13 January 2017; First published online 6 February 2017)

\begin{abstract}
Copyright resides with the authors in terms of the Creative Commons Attribution 4.0 South African License.
See: http://creativecommons.org/licenses/by/4.0/za

Condition of use: The user may copy, distribute, transmit and adapt the work, but must recognize the authors and the South African Journal of Animal Science.
\end{abstract}

\begin{abstract}
The Boschveld indigenous chicken is a breed that was developed in South Africa for rural household free-range production of meat and eggs. A performance test was carried out to identify their production characteristics when reared intensively, and to estimate the responses of the production characteristics to age, based on optimization functions. Day-old chicks were procured from the breeder and reared to point of lay, with 1432 layers generating the data. Parameters include egg weight $(\mathrm{g})$, egg number, hen day egg production (HDEP) $(\%)$, feed intake $(\mathrm{g} / \mathrm{b} / \mathrm{d})$, bodyweight $(\mathrm{kg})$, bodyweight gain $(\mathrm{g})$, feed conversion ratio (FCR), feed efficiency (FE), and mortality from start of lay until 44 weeks old. There was a significant effect of age on all these production parameters, except for FCR, which was not affected significantly by age as the birds grew. On fitting a prediction and optimization function using a regression model, these parameters showed significant linear response to age: HDEP, feed intake (g), and bodyweight $(\mathrm{kg})$, while significant quadratic responses were found in egg weight and FCR. The prediction model shows that at age 34, 52 and 65 weeks of lay, bodyweight, HDEP and feed intake respectively, would be optimized, while at age 36 and 43 weeks, FCR and egg weight respectively, would be optimized. This implies that Boschveld indigenous chicken production characteristics can be targeted at the appropriate age and can be optimized, given the age of lay that the birds are in.

Keywords: Egg laying, egg production, intensive production, native breed, optimization function, regression model

\#Corresponding author: melavicong@gmail.com

\section{Introduction}

Indigenous chickens play an important role in the livelihoods of most rural families in Africa. Despite increased use of commercial breeds by large-scale producers, around three quarters of chickens on the continent are indigenous breeds (CTA, 2007). Indigenous poultry farming with native breeds is practised in many developing and under-developed countries throughout the world (Bett et al., 2011; Magothe et al., 2012a; Magothe et al., 2012b), where the importance of native birds for rural economiesis immense (Magothe et al., 2012a; 2012b). Although these birds are being used for rural backyard poultry production, their genetic potential has not been fully exploited. Improvements of native breeds through selection are being carried out, but have to be given more importance (Dessie et al., 2011; Magothe et al., 2012b; Roothaert et al., 2011; Selvaggi et al., 2015). Indigenous chickens provide livelihood security to the family and secure the availability of food. Indigenous chicken breeds of African origin are well known for their tropical adaptability and disease resistance, but are considered of low productivity (Roothaert et al., 2011), although their plumage colour helps to protect them against predators. The first priority of today's rural poultry farmer is to have birds that not only lay more eggs, but that lay eggs with an optimum size, and grow to an optimum bodyweight with plumage of similar colour to indigenous birds.
\end{abstract}


The Boschveld chicken is derived from a cross of three indigenous breeds, namely Venda, Matabele and Ovambo. It was developed for the deep rural areas of South Africa and Africa. Farmers need a resilient chicken that can fend for itself, stay alive, and yield enough meat and eggs until it is slaughtered (Bosch, 2011). A major advantage of this breed is that it can feed on home-made rations on free range, thus cutting down the amount of feed that farmers have to give them. This study therefore is aimed at establishing the production characteristics of this breed of chicken when reared intensively, and identifying the responses of these production parameters as a result of age, using optimized functions.

\section{Materials and Methods}

This study was conducted between January and September 2013 at Itireleng Layer Farm in Bela-Bela in Limpopo, South Africa. The farm is located about $10 \mathrm{~km}$ south of Bela-Bela in theWaterberg district. The ambient temperature in the study area is above $30^{\circ} \mathrm{C}$ in summer and below $25^{\circ} \mathrm{C}$ in winter. Annual rainfall is between $550 \mathrm{~mm}$ and $600 \mathrm{~mm}$. The dry season occurs between April and October and the rainy season between October and March.

A total of 2467 indigenous Boschveld chickens were procured from the breeder at day old, and reared to point of lay at 21 weeks old. The chickens were reared in two houses, with all the equipment for rearing and production being provided from 3 weeks old. The troughs were attached to wire mesh that separated the pens to avoid spillage of feed. At the time of taking the measurements from the experiments, 1432 layers were left. Feed and water were provided ad libitum from starter to layer stage throughout the experiment.

Daily feed intake was determined by calculating the quantity of feed given minus the leftovers. Eggs were collected daily and stored. Then 100 were picked randomly and weighed individually with a sensitive weighing scale (AdamAFP-110L weighing scale sensitive from $1 \mathrm{mg}$ to $110 \mathrm{~g}$ ). Hen day egg production was determined by dividing the number of eggs produced by the number of chickens available and then multiplying by one hundred at the various ages of production:

$$
\text { Hen day egg production }(\mathrm{HDEP})(\%)=\frac{\text { number of eggs produced }}{\text { number of hens available }} \times 100
$$

The bodyweight of the chicken was also taken, starting from 21 weeks old until 44 weeks old. This was done by randomly sampling 50 birds in the two houses, and taking their weight with a sensitive scale. Bodyweight gain was measured as the difference between current weekly bodyweight and the previous weekly bodyweight. The FCR was measured as the ratio between feed intake and bodyweight gain, and FE was measured as the ratio of bodyweight gain and feed intake. Mortality was recorded every day from the two houses.

The raw data were first analysed with the descriptive statistics procedure (SAS, 2010), to establish the mean, standard deviation, coefficient of variation, and minimum and maximum values of the parameters. The effects of age on the production characteristics of Boschveld chicken were analysed with the general linear model (GLM) procedures of the statistical analysis system (SAS, 2010). The statistical model was:

$$
Y_{\mathrm{ijk}}=\mu+\mathrm{T}_{1}+\sum_{\mathrm{ijk}}
$$

Where: $Y_{\mathrm{ijk}}=$ the overall observation (production)

$\mu=$ population means

$\mathrm{T}_{1}=$ effect of different ages

$\sum_{\mathrm{ijk}}=$ residual effect

Student-Newman-Keuls (SNK) method for multiple comparisons was used to separate the significant means between the age treatments according to SAS (2010).

The optimization function was fitted to understand the relationship and prediction of response of the parameters to age. The significant age-related effects in the chicken production parameters such as egg weight (g) egg number, percentage lay $(\%)$, feed intake $(\mathrm{g} / \mathrm{b} / \mathrm{d})$, bodyweight $(\mathrm{kg})$, bodyweight gain $(\mathrm{g})$, FCR, $\mathrm{FE}$, and mortality were modelled using the regression function and the linear and quadratic models gave the best fit. The models were:

$$
\begin{aligned}
& Y=a+b x+e \\
& Y=a+b_{1} x+b_{2} x^{2}+e
\end{aligned}
$$

Where $Y=$ chicken production characteristics

$a=$ intercept on $Y$-axis

$b=$ coefficients of the independent variable $x$, which is the age of chicken in weeks, $-b_{1} / 2 b_{2}$, which is the value of $x$ that gives the optimum age in weeks

The linear and quadratic models were fitted to the experimental data by the non-linear model (NLIN) procedure of SPSS (2007). The two models were used, because they gave the best fit, hence, better prediction of optimum age for production parameters. 


\section{Results}

A general progressive increment in the values of the production parameters was observed as the age of the Boschveld indigenous chickens increased from 21 weeks to 44 weeks old (see Table 1 \& 2). Hen day egg production (\%), egg number, and feed intake means initially dropped numerically at 28 weeks old, but picked up again from 32 weeks old to continue the general progressive increment in value as age increased. Mortality and FCR consistently showed a high coefficient of variation values, indicating a wide variability in their values. The egg weight increased from $46.07 \mathrm{~g}$ at 24 weeks to $52.29 \mathrm{~g}$ at 44 weeks, with medium to high coefficient of variation. However, FE decreased as the animals increased in age, from 2.11 at 28 weeks to 1.88 at 44 weeks. Moreover, parameters such as egg weight, egg number, HDEP, feed intake, bodyweight, bodyweight gain, $\mathrm{FE}$ and mortality were affected $(P<0.05)$ by age (Table 3$)$

Table 1 Descriptive statistics of Boschveld chicken production characteristics from 24 to 32 weeks old

\begin{tabular}{|c|c|c|c|c|c|c|c|}
\hline Age (weeks) & Parameter ${ }^{*}$ & Number of chickens & Mean & Std Dev & CV & Min & $\operatorname{Max}$ \\
\hline \multirow[t]{9}{*}{24} & Egg weight (g) & 100 & 46.07 & 5.53 & 11.99 & 35.40 & 62.40 \\
\hline & Egg number (/layers) & 1432 & 255.30 & 28.58 & 11.19 & 206 & 306 \\
\hline & $\operatorname{HDEP}(\%)$ & 1432 & 17.84 & 2.00 & 11.19 & 14.40 & 21.28 \\
\hline & Feed intake (g/b/d) & 1432 & 86.49 & 10.56 & 12.21 & 53.81 & 94.34 \\
\hline & Bodyweight (kg) & 50 & 1.65 & 0.25 & 14.99 & 0.97 & 2.03 \\
\hline & Bodyweight gain (g) & 50 & - & - & - & - & - \\
\hline & FCR & 50 & - & - & - & - & - \\
\hline & FE & 50 & - & - & - & - & - \\
\hline & Mortality & 1 & 0.03 & 0.18 & 556.78 & 0.00 & 1.00 \\
\hline \multirow[t]{9}{*}{28} & Egg weight (g) & 100 & 46.74 & 1.46 & 3.13 & 43.30 & 50.00 \\
\hline & Egg number (/layers) & 1426 & 111.90 & 54.85 & 49.02 & 5.00 & 200.00 \\
\hline & HDEP (\%) & 1426 & 7.84 & 3.83 & 48.85 & 0.35 & 13.99 \\
\hline & Feed intake (g/b/d) & 1426 & 79.29 & 16.33 & 20.60 & 52.04 & 93.27 \\
\hline & Bodyweight (kg) & 50 & 1.80 & 0.18 & 10.23 & 1.27 & 2.08 \\
\hline & Bodyweight gain (g) & 50 & 170.48 & 122.98 & 72.13 & -3.00 & 430.00 \\
\hline & FCR & 50 & 0.56 & 1.31 & 231.88 & -4.12 & 2.29 \\
\hline & FE & 50 & 2.11 & 1.77 & 84.12 & -0.03 & 7.79 \\
\hline & Mortality & 11 & 0.37 & 0.49 & 133.67 & 0.00 & 1.00 \\
\hline \multirow[t]{9}{*}{32} & Egg weight (g) & 100 & 49.99 & 2.82 & 5.65 & 43.85 & 57.03 \\
\hline & Egg number (/layers) & 1005 & 353.23 & 64.10 & 18.15 & 251 & 450.00 \\
\hline & HDEP (\%) & 1005 & 35.34 & 7.41 & 20.98 & 24.56 & 46.58 \\
\hline & Feed intake (g/b/d) & 1005 & 118.41 & 3.92 & 3.31 & 112.20 & 126.80 \\
\hline & Bodyweight (kg) & 50 & 1.94 & 0.14 & 7.05 & 1.62 & 2.13 \\
\hline & Bodyweight gain (g) & 50 & 114.87 & 114.42 & 99.61 & -11.00 & 430.00 \\
\hline & FCR & 50 & 0.81 & 3.28 & 405.47 & -9.87 & 4.73 \\
\hline & FE & 50 & 1.34 & 1.28 & 94.86 & -0.19 & 4.76 \\
\hline & Mortality & 119 & 3.97 & 1.99 & 50.20 & 0.00 & 8.00 \\
\hline
\end{tabular}

${ }^{*}$ FCR: feed conversion ratio, FE: feed efficiency, CV: coefficient of variation, HDEP: hen day egg production

Egg weight was significantly highest at 44 weeks old $(52.29 \mathrm{~g})$ and lowest at 24 weeks $(46.07 \mathrm{~g})$. This was expected because chicken production parameters are influenced linearly by age. Egg number, however, dropped significantly $(P<0.05)$ from 24 to 28 weeks, and picked up drastically at 32 weeks, maintaining the trend at 36 weeks, but dropped again at 40 weeks, only to pick up again at 44 weeks old. 
Table 2 Descriptive statistics of Boschveld chicken production characteristics from 36 to 44 weeks old

\begin{tabular}{|c|c|c|c|c|c|c|c|}
\hline Age (weeks) & Parameter* & Number of chicken & Mean & Std Dev & CV & Min & Max \\
\hline \multirow[t]{9}{*}{36} & Egg weight (g) & 100 & 52.62 & 10.92 & 20.75 & 37.93 & 156.98 \\
\hline & Egg number (/layers) & 849 & 350.57 & 62.05 & 17.70 & 251.00 & 450.00 \\
\hline & HDEP (\%) & 849 & 41.58 & 8.78 & 21.11 & 28.92 & 56.04 \\
\hline & Feed intake (g/b/d) & 849 & 112.45 & 9.41 & 8.44 & 90.10 & 125.78 \\
\hline & Bodyweight (kg) & 50 & 2.06 & 0.04 & 2.06 & 1.97 & 2.18 \\
\hline & Bodyweight gain (g) & 50 & 135.67 & 131.93 & 97.24 & -30.00 & 450.00 \\
\hline & FCR & 50 & 1.80 & 4.37 & 243.41 & -11.73 & 11.90 \\
\hline & FE & 50 & 1.15 & 1.13 & 97.60 & -0.24 & 3.89 \\
\hline & Mortality & 104 & 3.47 & 1.59 & 45.91 & 0.00 & 8.00 \\
\hline \multirow[t]{9}{*}{40} & Egg weight (g) & 100 & 53.59 & 8.81 & 16.43 & 47.12 & 138.58 \\
\hline & Egg number (/layers) & 720 & 290.61 & 79.40 & 27.32 & 120.00 & 430.00 \\
\hline & HDEP (\%) & 720 & 40.09 & 9.97 & 24.88 & 17.29 & 57.64 \\
\hline & Feed intake (g/b/d) & 720 & 126.77 & 7.34 & 5.79 & 114.29 & 142.01 \\
\hline & Bodyweight (kg) & 50 & 2.14 & 0.04 & 1.80 & 2.07 & 2.25 \\
\hline & Bodyweight gain (g) & 50 & 72.13 & 52.53 & 72.83 & -63.00 & 153.00 \\
\hline & FCR & 50 & 1.48 & 2.17 & 146.26 & -3.42 & 9.01 \\
\hline & $\mathrm{FE}$ & 50 & 0.65 & 0.48 & 74.95 & -0.66 & 1.39 \\
\hline & Mortality & 104 & 3.35 & 1.72 & 51.37 & 0.00 & 9.00 \\
\hline \multirow[t]{9}{*}{44} & Egg weight (g) & 100 & 52.29 & 3.40 & 6.51 & 43.80 & 63.30 \\
\hline & Egg number (/layers) & 666 & 373.65 & 91.12 & 24.29 & 180.00 & 520.00 \\
\hline & HDEP (\%) & 666 & 56.06 & 13.55 & 24.18 & 27.23 & 77.73 \\
\hline & Feed intake (g/b/d) & 666 & 129.35 & 5.87 & 4.54 & 118.44 & 143.50 \\
\hline & Bodyweight (kg) & 50 & 2.38 & 0.09 & 3.60 & 2.18 & 2.60 \\
\hline & Bodyweight gain (g) & 50 & 237.23 & 89.14 & 37.58 & 34.00 & 450.00 \\
\hline & FCR & 50 & 0.68 & 0.60 & 88.90 & 0.26 & 3.74 \\
\hline & FE & 50 & 1.88 & 0.73 & 38.85 & 0.27 & 3.81 \\
\hline & Mortality & 26 & 0.84 & 1.49 & 177.11 & 0.00 & 6.00 \\
\hline
\end{tabular}

*FCR: feed conversion ratio, FE: feed efficiency, CV: coefficient of variation, HDEP: hen day egg production

This shows the vagaries of production, which could be caused by factors such as environment, feed and health condition of the animals. In the same vein, mortality records showed a significant $(P<0.05)$ increase from 24 to 40 weeks, which was not significantly different, but dropped again at age 44 weeks. This might have been because of being reared intensively, as opposed to their natural free range system. The HDEP $(\%)$ showed a significant $(P<0.05)$ drop from 24 to 28 weeks, but picked up significantly $(P<0.05)$ until 44 weeks old. Feed intake was also significantly linearly influenced by age, as shown in Table 3. At week 28 , the feed intake was lower than at 24 weeks. This might be due to a challenge to the birds that could be ascribed to their genetics. Bodyweight, however, was influenced linearly as age increased, with week 24 being the least, andweek 44 being heaviest. The birds gained most at week 44, followed by weeks 28,32 and 36, but gained least at 40 weeks. This could be owing to their inherent nature. However, FCR was not significantly affected by the age of the chicken, implying that the birds converted their feed in the same way until 44 weeks old. Meanwhile, FE was significantly higher at 28 weeks, and least at 36 and 40 weeks old. This might not be unconnected to the least feed consumed at 28 weeks, while gaining significantly higher bodyweight at the same age.

When subjected to regression function, the values of egg number, HDEP, feed intake, bodyweight, and bodyweight gain fitted into a linear model. Egg weight, FCR, FE and mortality fitted into a quadratic model (Table 4). 
Table 3 Effect of age on production parameters in Boschveld chicken

\begin{tabular}{lccccccc}
\hline \multirow{2}{*}{ Parameters } & \multicolumn{7}{c}{ Age (weeks) } \\
\cline { 2 - 8 } & 24 & 28 & 32 & 36 & 40 & 44 & SEM \\
\hline Egg weight (g) & $46.07^{\mathrm{c}}$ & $46.74^{\mathrm{c}}$ & $49.99^{\mathrm{b}}$ & $52.62^{\mathrm{a}}$ & $53.59^{\mathrm{a}}$ & $52.29^{\mathrm{a}}$ & 0.288 \\
Egg number (/layers) & $255.30^{\mathrm{c}}$ & $111.90^{\mathrm{d}}$ & $353.23^{\mathrm{a}}$ & $350.57^{\mathrm{a}}$ & $290.61^{\mathrm{b}}$ & $373.65^{\mathrm{a}}$ & 8.200 \\
HDEP (\%) & $17.83^{\mathrm{d}}$ & $7.84^{\mathrm{e}}$ & $35.34^{\mathrm{c}}$ & $41.48^{\mathrm{b}}$ & $40.09^{\mathrm{b}}$ & $56.06^{\mathrm{a}}$ & 1.340 \\
Feed intake (g/b/d) & $86.50^{\mathrm{d}}$ & $79.29^{\mathrm{e}}$ & $111.41^{\mathrm{b}}$ & $112.45^{\mathrm{c}}$ & $126.77^{\mathrm{a}}$ & $129.35^{\mathrm{a}}$ & 1.594 \\
Bodyweight (kg) & $1.65^{\mathrm{f}}$ & $1.80^{\mathrm{e}}$ & $1.94^{\mathrm{d}}$ & $2.06^{\mathrm{c}}$ & $2.14^{\mathrm{b}}$ & $2.38^{\mathrm{a}}$ & 0.016 \\
Bodyweight gain (g) & - & $170.48^{\mathrm{b}}$ & $114.87^{\mathrm{bc}}$ & $135.67^{\mathrm{bc}}$ & $72.13^{\mathrm{c}}$ & $237.23^{\mathrm{a}}$ & 9.631 \\
FCR & - & 0.56 & 0.81 & 1.80 & 1.48 & 0.68 & 0.219 \\
FE & - & $2.11^{\mathrm{a}}$ & $1.34^{\mathrm{bc}}$ & $1.15^{\mathrm{c}}$ & $0.65^{\mathrm{c}}$ & $1.88^{\mathrm{ab}}$ & 0.103 \\
Mortality & $0.03^{\mathrm{b}}$ & $0.37^{\mathrm{b}}$ & $3.97^{\mathrm{a}}$ & $3.47^{\mathrm{a}}$ & $3.35^{\mathrm{a}}$ & $0.84^{\mathrm{b}}$ & 0.158
\end{tabular}

abcdef Means on the same row with different superscriptsare significantly different $(P<0.05)$, HDEP: hen day egg production, FCR: feed conversion ratio, FE: feed efficiency.

Table 4 Response in terms of age to production characteristics in Boschveld indigenous chicken using regression function

\begin{tabular}{lccccc}
\hline Parameters & Optimal Age & $\mathrm{R}^{2}$ value & $\mathrm{P}$ - values & Function type & Significance \\
\hline Egg weight $(\mathrm{g})$ & 43.36 & 0.913 & 0.03 & Quadratic & $*$ \\
Egg number & 63.70 & 0.381 & 0.19 & Linear & $\mathrm{Ns}$ \\
HDEP $(\%)$ & 51.88 & 0.813 & 0.01 & Linear & $* *$ \\
Feed intake $(\mathrm{g} / \mathrm{b} / \mathrm{d})$ & 65.00 & 0.863 & 0.01 & Linear & $* *$ \\
Bodyweight $(\mathrm{kg})$ & 34.00 & 0.984 & 0.001 & Linear & $* *$ \\
Bodyweight gain $(\mathrm{g})$ & 64.23 & 0.359 & 0.21 & Linear & $\mathrm{Ns}$ \\
FCR & 36.75 & 0.805 & 0.05 & Quadratic & $*$ \\
FE & 37.25 & 0.152 & 0.78 & Quadratic & $\mathrm{Ns}$ \\
Mortality & 35.15 & 0.835 & 0.651 & Quadratic & $\mathrm{Ns}$
\end{tabular}

${ }^{*} \operatorname{Pr}<95 \%,{ }^{* *} \operatorname{Pr}<99 \%,{ }^{* * *} \operatorname{Pr}<99.99 \%$, NS:not significant, HDEP: hen day egg production, FCR: feed conversion ratio, FE: feed efficiency.

Not all the parameters elicited a significant response in terms of age, except HDEP, feed intake and bodyweight for linear function, and egg weight and FCR for quadratic function. The linear responses in terms of egg number, HDEP, feed intake, bodyweight, and bodyweight gain to age are shown in Figures $1 \mathrm{~A}-$ $E$ with the linear equations $Y=3.70+2.10 x, Y=71.86+2.56 x$ and $Y=1.52+0.034 x$ reflecting the significant relationship between age and HDEP, feed intake and body weight only (Figures 1B-D), while the linear equations $Y=176.69+8.04 x$ and $Y=30.54+6.51 x$ reflecting the non-significant relationship between age and egg number and body weight gain (Figures $1 \mathrm{~A}$ and $\mathrm{E}$ ). However, the quadratic response in terms of egg weight, FCR, FE, and mortality to age had the following equations: $Y=41.63+0.981 x-0.21 x^{2}, Y=-1.34-$ $0.335 x-0.01 x^{2}, Y=0.152+0.138 x-0.004 x^{2}$ and $Y=-4.10+1.00 x+-0.033 x^{2}$ (Figures 2A-D). Only egg weight and FCR were significant $(P<0.05)$. Most of the egg weight responses occurred between 25 and 44 weeks, but the maximum was reached at 43.4 weeks old (Fig 2A). The FCR showed most response between 25 and 40 weeks, but with the maximum at 37 weeks old (Fig $2 B$ ). The high $R^{2}$ values for the egg number and FCR of $91.3 \%$ and $80.5 \%$, respectively, show a strong relationship between age and these parameters. 


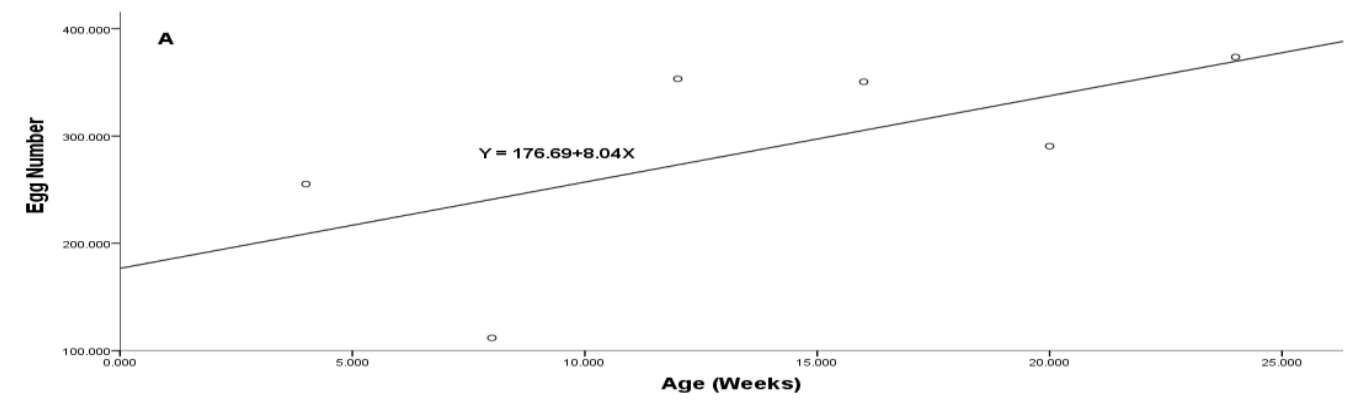

Figure 1(A) Linear function best fitting optimum age and (A) egg number

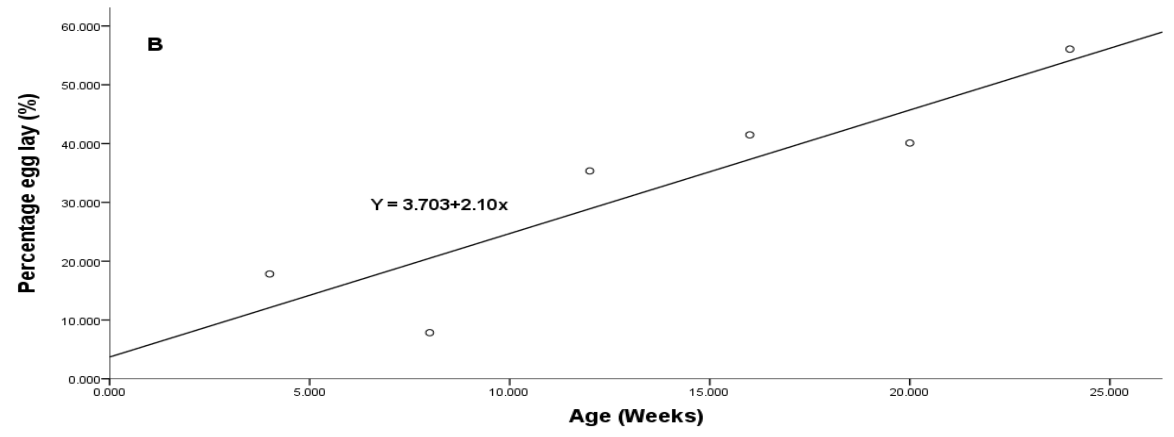

Figure 1(B) Linear function best fitting optimum age and (B) hen day egg production.

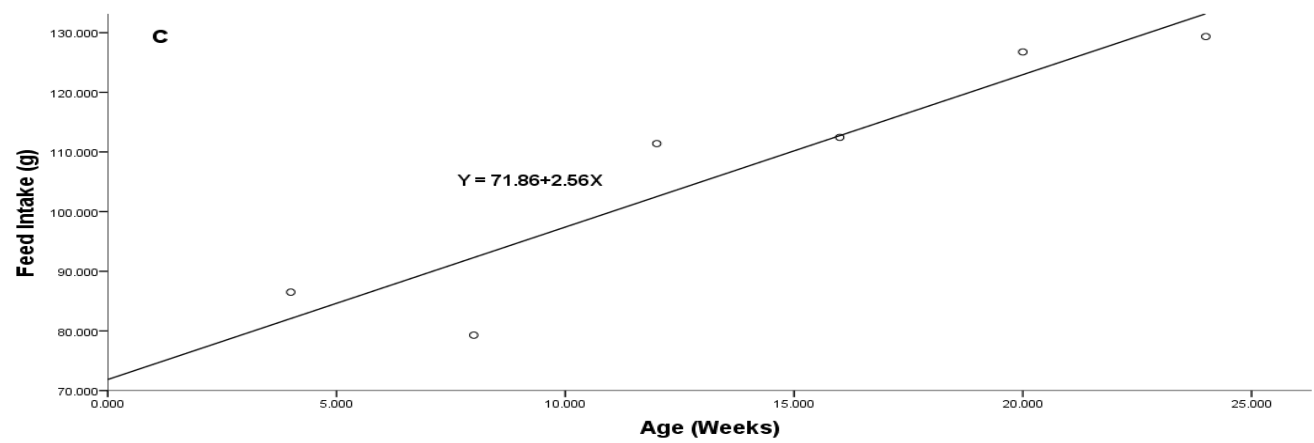

Figure $1(\mathrm{C})$ Linear function best fitting optimum age and(C) feed intake 


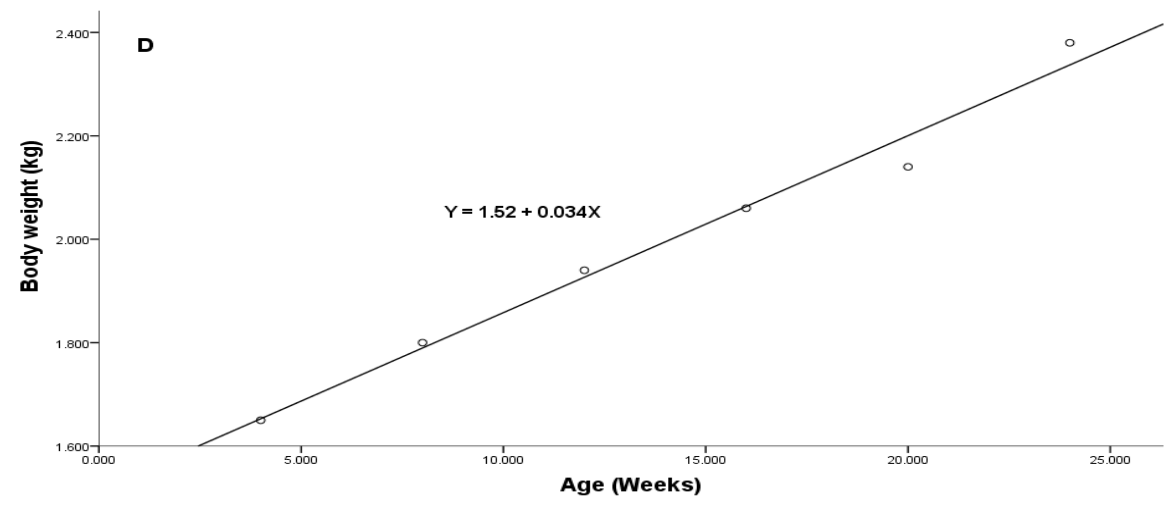

Figure 1(D) Linear function best fitting optimum age and (D) bodyweight

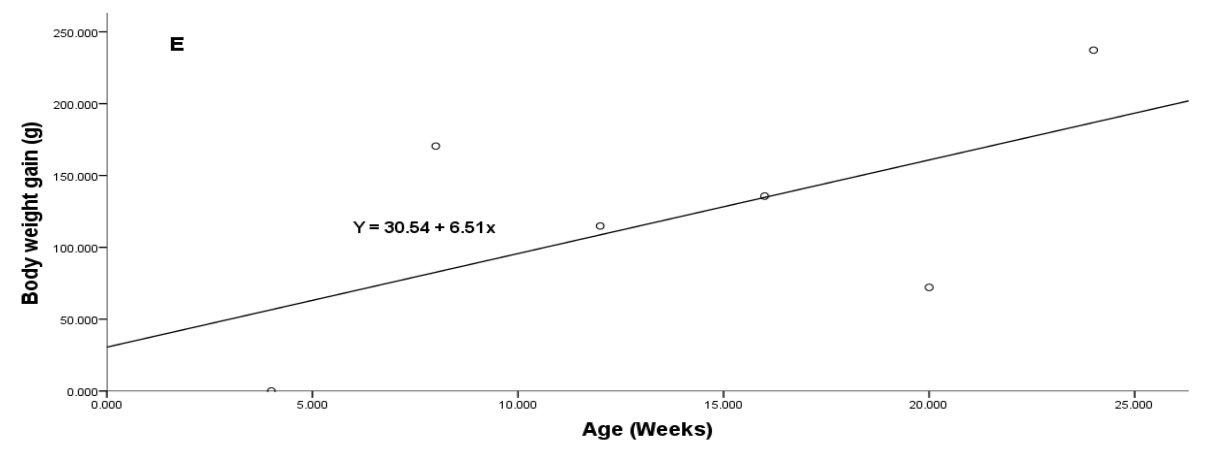

Figure $1(E)$ Linear function best fitting optimum age and $(E)$ bodyweight gain

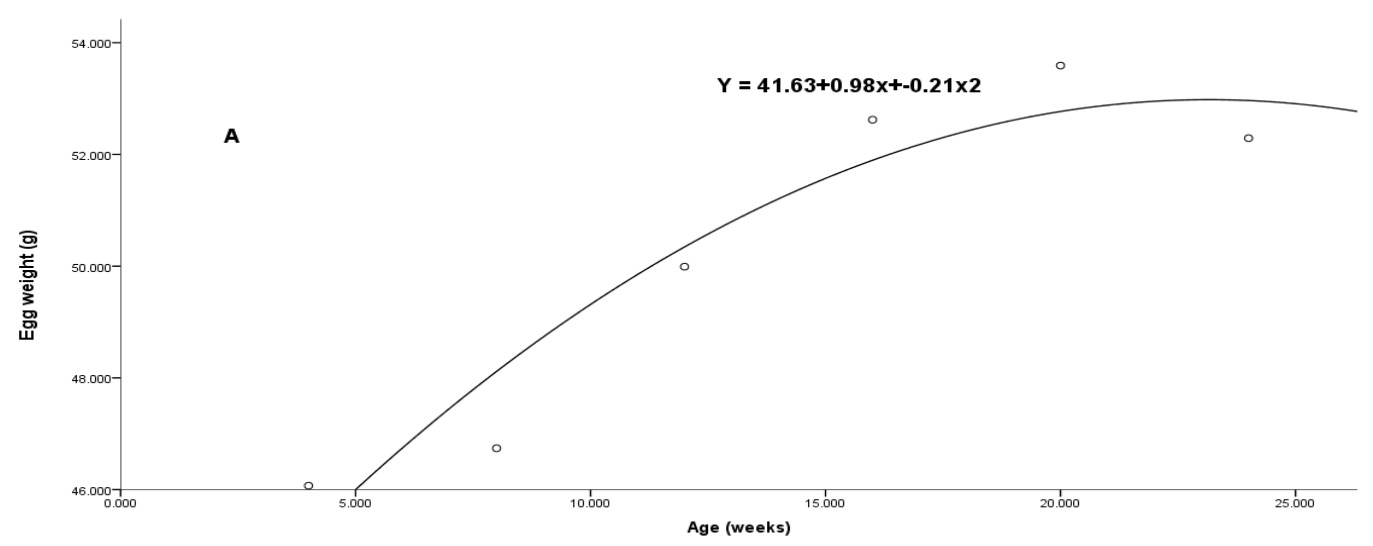

Figure 2 (A) Quadratic function best fitting optimum age and (A) egg weight 


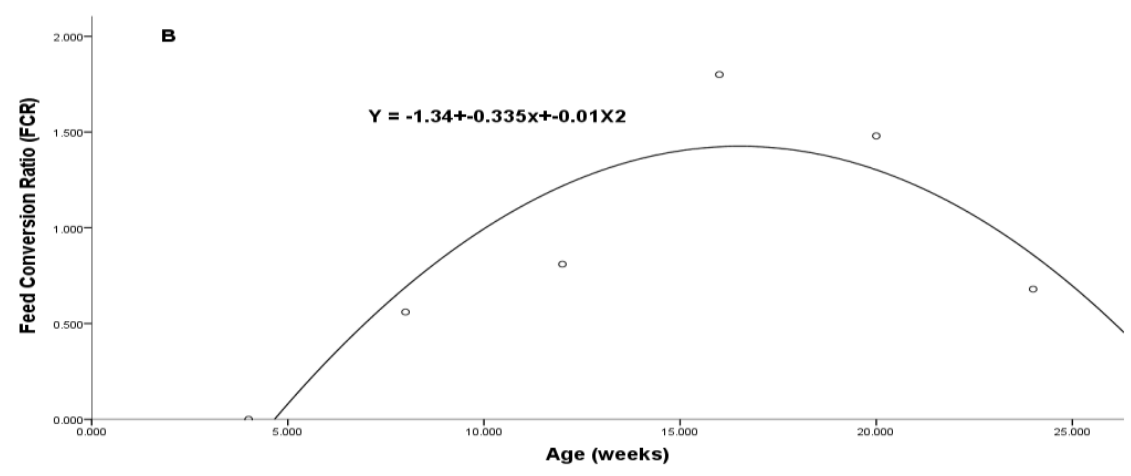

Figure 2 (B) Quadratic function best fitting optimum age and (B) feed conversion ratio

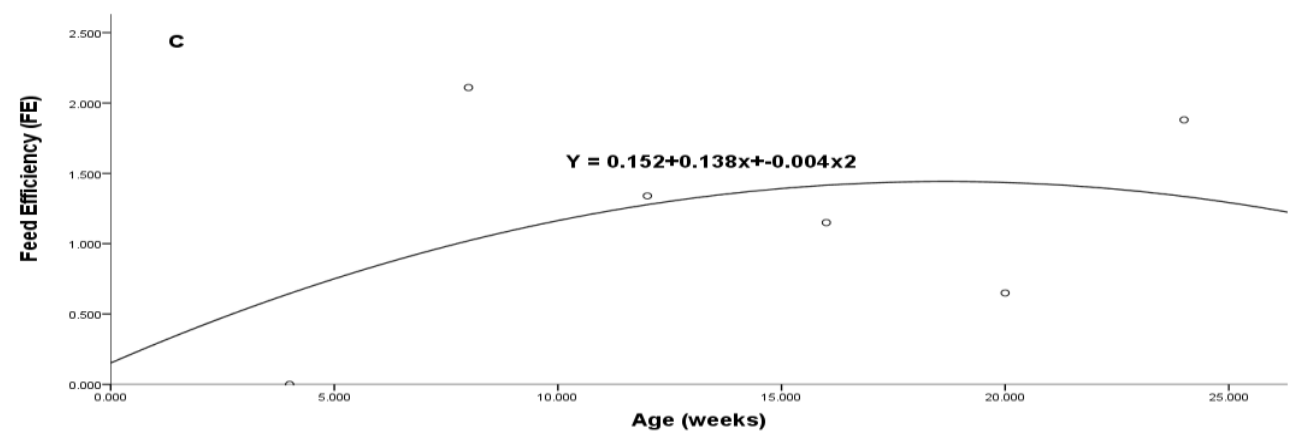

Figure $2(\mathrm{C})$ Quadratic function best fitting optimum age and (C) feed efficiency

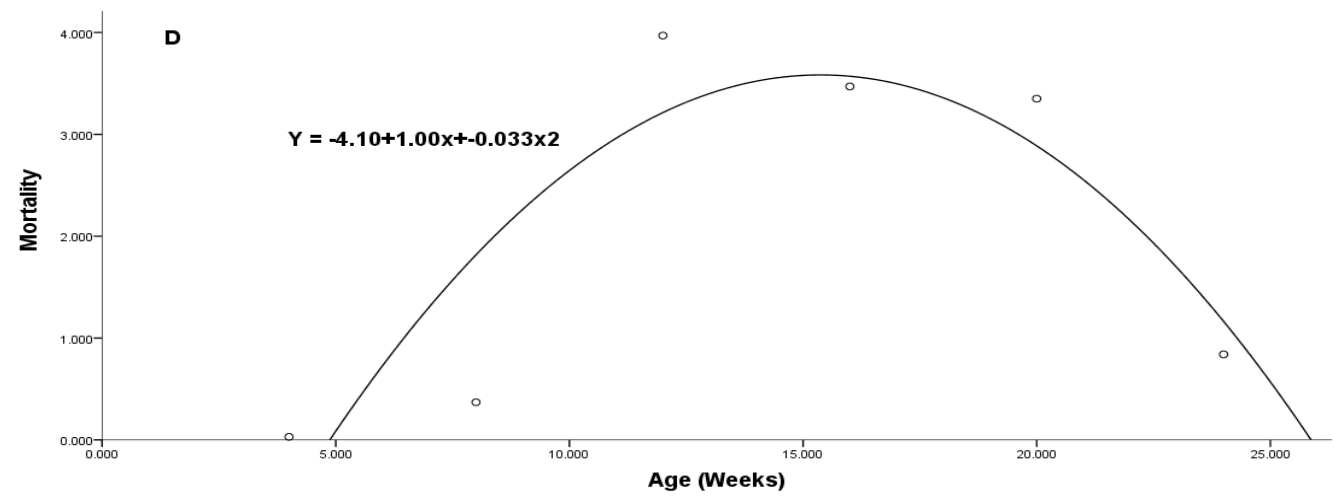

Figure 2 (D) Quadratic function best fitting optimum age and (D) mortality 


\section{Discussion}

The production parameters measured in this study for the Boschveld indigenous chicken showed variation in their expression. Egg weight, which lay between $46 \mathrm{~g}$ at 24 weeks old and $54 \mathrm{~g}$ at 40 weeks old, could be classified as medium ( $43 \mathrm{~g}-51 \mathrm{~g})$ and large $(51 \mathrm{~g}-59 \mathrm{~g})$, according to McNamara (2010). This is higher than values reported by Islam et al. (2014) for the Vanaraja breed, namely $48.32 \pm 0.21 \mathrm{~g}$ at 32 weeks, and $53.07 \pm 0.24 \mathrm{~g}$ at 40 weeks old,and an indigenous breed, namely $27.85 \pm 0.04 \mathrm{~g}$ at 32 weeks and $32.06 \pm 0.07 \mathrm{~g}$ at 40 weeks old, all reared under an extensive system. Similarly, Khawaja et al. (2012) reported average egg weights of $44.42 \mathrm{~g}, 43.35 \mathrm{~g}$, and $56.83 \mathrm{~g}$ for Desi, Fayoumi and Rhode Island Red (RIR) breeds of chicken, respectively, reared up to 72 weeks old, which were comparatively lower than values recorded by the Boschveld chickens. Although the Boschveld birds came into lay at 21 weeks old (147 days), the Varanaja, an indigenous breed of India, and the Rakai, an indigenous breed of Uganda, came into lay at 187.45, 201.31 and 154 days, respectively (Islam et al., 2014; Roothaert et al., 2011). This shows that Boschveld chickens come into lay earlier than the breeds reported by Islam et al. ( 2014) and Roothaert et al. (2011). This value of 147 days is higher than those reported by Grobbelaar et al.(2010) for the Potchefstroom Koekoek (138.5 days), Venda (139.0 days) and Ovambo (134.5 days) breeds. However,in a comparative study in Pakistan,Khawaja et al. (2012) reported values of 204, 135 and 147 days old at first egg for Desi, Fayoumi and RIR breeds of chicken reared intensively.According to Khawaja et al. (2012), the variation in age at first egg among breeds may be because of differences in bodyweight prior to the onset of sexual maturity. This implies that age at first egg is correlated with bodyweight according to breeds: the smaller the bodyweight, the earlier the age at sexual maturity, as with the Fayoumi. These differences could be attributed to factors such as the rearing process and genetic differences.

The egg number produced by Boschveld chickens lay between 112 and 374 , with a HDEP of $7.8 \%$ to $56.56 \%$ within 44 weeks old. Grobbelaar et al. (2010) reported a significant difference $(P<0.05)$ between Potchefstroom Koekoek, Naked Neck, Venda and Ovambo for number of eggs per hen per year, with values of 195.9, 138.9, 153.7, and 125.5 eggs, respectively. However, this study did not report the laying performance of the birds through one year, but for only 44 weeks, which showed the potential to reach a close value or higher.

The feed intake of the Boschveld indigenous layers ranged from $79 \mathrm{~g}$ per day to $129 \mathrm{~g}$ per day for the 44 weeks of study. Khawaja et al. (2012) reported a daily feed intake (g/bird) of $132.80 \mathrm{~g}, 120 \mathrm{~g}$ and 136.07 $\mathrm{g}$ for Desi, Fayoumi and RIR breeds of chicken, respectively, up to 72 weeks old. In comparison with the Boschveld breed, these values were higher in the Desi and RIR, but lower in Fayoumi Okoro et al. (2005) reported that several factors influence feed intake in laying hens, which include environment, water, nutrition, genotype, health, production state, and management practices. Meanwhile the mean bodyweight of the chickens studied ranged from $1.65 \mathrm{~kg}$ to $2.39 \mathrm{~kg}$ at 44 weeks old. This is lighter than the values reported by Islam et al. (2014) and Roothaert et al. (2011)in the Varanaja and Rakai indigenous chicken breeds of India and Uganda, respectively. A value of $2.98 \mathrm{~kg}$ was reported at 40 weeks for Vanaraja reared extensively, and $2.5 \mathrm{~kg}$ at 45 weeks for the Rakai when reared extensively. However, the Boschveld is heavier than the pure indigenous chicken of India, which weighs $0.78 \mathrm{~kg}$ and $1.27 \mathrm{~kg}$ at 20 and 40 weeks, respectively, as well as the Desi, Fayoumi and RIR, with weights of $1.15 \mathrm{~kg}, 1.14 \mathrm{~kg}$ and $1.61 \mathrm{~kg}$, respectively (Khawaja et al., 2012)at 72 weeks old. This means that the Boschveld indigenous chicken is a heavy breed. As it ages, egg weight and bodyweight increase. Bodyweight gain over a four-week period was also estimated and lay between $170.48 \mathrm{~g}$ at 28 weeks and $237.23 \mathrm{~g}$ at 44 weeks. This sudden drop in bodyweight gain at 40 weeks after a higher gain at 36 weeks is unprecedented, as the birds then gained almost three times the bodyweight of $237 \mathrm{~g}$ at 44 weeks. This could be owing to the drop in feed intake, as well as the FCR, in the same period. This might not be unconnected with the report of Dessie et al. (2011) that bodyweight and egg weight show a positive genetic correlation with a significantly higher and better production in lightweight hens, which produce higher egg numbers and lower FCR values than those of heavier weight.

The FCR value was below 2 throughout the stages of lay, while the FE values were between 0.65 and 2.11. The FCR, which is the ratio of feed intake and bodyweight gain, indicated a low value, and FE, which is the ratio of bodyweight gain and feed intake, also showed a low value. Khawaja et al. (2012) reported FCR ranging from 3.5 to 7.5 in Desi, Fayoumi and RIR breeds of chicken, with higher values at the growing stage, and lower values at the production stage. These values are higher than those of the animals used in this study, even as the average weight of the birds at 0-20 weeks of lay was $1.23 \mathrm{~kg}$, while the Boschveld was $2.38 \mathrm{~kg}$ at 44 weeks of lay. This might be due to genetic differences in the chicken. Meanwhile FE values ranging from 5.02 to 8.70 were reported by Khawaja et al. (2012) in the same study, with FE defined as a ratio of feed intake and egg mass. In most instances, FE is defined as the ratio of feed and the parameter of choice, while in this study, the bodyweight gain and feed were chosen. 
The mortality of Boschveld indigenous chickens ranged between 0.03 at 24 weeks old and 3.97 at 32 weeks of lay. Mortality was recorded mainly at the beginning of lay of this chicken breed as it dropped significantly until 44 weeks old. Islam et al. (2014) reported a mortality value of 1.04 from 6 to 30 weeks, and 1.03 from 31 to 52 weeks of lay in Varanaja chickens, while in indigenous chickens of India, he reported a value of 3.61 at 6 to 30 weeks and 1.06 at 31 to 52 weeks. These values are low, particularly for the Varanaja, while the indigenous breed exhibited values close to those reported in this study. This may be because the chickens in the current study were raised intensively, while those reported by Islam et al. (2014) were reared extensively. The rearing method could thus act as a mortality restriction.

Several studies applied the regression model to explain traits of economic significance such as growth, milk and egg production, with the most widely accepted forms of empirical function being the linear and non-linear models (Narinc et al., 2014). Numerous studies have been conducted to investigate carcass yields and carcass quality, as well as egg production from poultry, largely using Gompertz, logistic, Richards and Von Bertalanffy models. Almost all of these models are utilized generally to describe growth in poultry (Selvaggi et al., 2015). They vary not only in the number of parameters, but also in their flexibility around the point of inflection (Kuhi et al., 2010; Narinc et al., 2010; Selvaggi et al., 2015). However, none of these studies reported on optimizing the egg production parameters of Boschveld indigenous chicken from 21 week until 44 weeks of lay.Savegnago et al. (2012)recorded that non-linear regression and multi-stage modelling methods couldbe used in modelling egg production. Among the non-linear regression models, Adams-Bell and logistic are reputed to be good egg production models, with the Adams-Bell model or a simple linear regression exhibiting better fitting performance from peak production to 20 or 24 weeks of production (Faridi et al., 2011). By modelling egg yields of commercial poultry breeder flocks with AdamsBell, modified compartmental, logistic and Narushin-Takma functions, Faridi et al. (2011) stated that all four models gave good results according to goodness of fit. They suggested that the Narushin-Takma model was a good alternative for modelling yield of eggs. Savegnago et al. (2011) analysed annual egg production of White Leghorn strains with logistic and neural network models. It was concluded that the neural networks could be used as an alternative tool to fit egg production. In another study, conducted by Savegnago et al. (2011), weekly egg production rates of selected (for egg productionand egg quality) and non-selected (random bred control) lines of a White Leghorn henpopulation were used to fit non-linear (logistic, compartmental, modified compartmental, McMillan, McNally) and multiphasic (segmented polynomial, persistency) models. According to the goodness of fit of the models, the logistic, modified compartmental, segmented polynomial, and persistency models presented the best goodness of fit. Meanwhile, this study used linear and quadratic regression functions to analyse egg production parameters and age, and found significant best of fit depending on the model of choice. With a significant linear fit for HDEP, feed intake and bodyweight, and significant quadratic fit for egg weight and FCR only, this implies that these parameters would be optimum at age 34, 52 and 65 weeks for linear and 37 and 43.4 weeks for quadratic, respectively. These are projections within and outside the period of this study which could influence farmers to decide using the Boschveld indigenous breed of chicken to improve productivity by targeting these ages in order to achieve enhance HDEP, feed intake, body weight and FCR.

\section{Conclusion}

The production characteristics of Boschveld indigenous chickens of South Africa have not been documented before now. This study shows the productivity of the breed from 21 weeks commencement of lay to 44 weeks into lay. It identifies the Boschveld as a heavy breed. At week 44 of lay, it attained a bodyweight of $2.4 \mathrm{~kg}$, which is relatively heavy. As shown by the optimization function, the birds continued to increase in bodyweight until end of laying cycle. Furthermore, this study brought to the fore the ability of this breed to continually increase its feed intake and HDEP until 52 and 65 weeks, respectively, based on optimization function. Although the literature has shown that layers lay continually up to a peak before production drops, the optimization function shows that the egg size reached its peak at 43.4 weeks with an average weight of $52.3 \mathrm{~g}$, which could be economical if one considers using the breed for egg and table meat production.

\section{Acknowledgements}

The authors wish to acknowledge the active participation of the Department of Agriculture, Bela-Bela Municipality, Limpopo, South Africa, in this project.

\section{Authors' Contributions}

Conception and design: RKE, MTH \& MCA; data collection, analyses and drafting of paper: OVMO, RKE \& MTH; critical revision: MEF \& OVMO; critical revision and final approval of version to be published: MCA, MEF \& OVMO.

\section{Conflict of Interest Declaration}


The authors certify that they have no affiliation with or involvement in any organization or entity with financial or non-financial interest in the subject matter or materials discussed in this manuscript.

\section{References}

Bett, H., Peters, K. \& Bokelmann, W., 2011. Hedonic price analysis to guide in breeding and production of indigenous chickens in Kenya. Livest. Res. Rural Dev. 23, 23-28.

Bosch, M., 2011. Farmers Weekly for Boschveld free range chickens(WWW document). www.boschveld.co.za/farmersweekly. URL www.boschveld.co.za/farmers-weekly/.Accessed 18 August 2016.

CTA, 2007. Improved practices in rearing indigenous chickens. 3rd ed. ACP-EU Tech. Centre for Agric. and Rural Coop. CTA, Wageningen. Doi:10.17660/ActaHortic.2007.752.47

Dessie, T., Taye, T., Dana, N., Ayalew, W. \& Hanotte, O., 2011. Current state of knowledge on phenotypic characteristics of indigenous chickens in the tropics. World's Poult. Sci. J. 67, 507-516. Doi:10.1017/S0043933911000559

Faridi, A., Mottaghitalab, M., Rezaee, F. \& France, J., 2011. Narushin-Takma models as flexible alternatives for describing economic traits in broiler breeder flocks. Poult. Sci. 90, 507-515.

Grobbelaar, J., Sutherland, B. \& Molalakgotla, N., 2010. Egg production potential of certain indigenous chicken breeds from South Africa. Anim. Gen. Resources Info. 46, 25-32. Doi:10.1017/S2078633610000664

Gueye, E., 1998. Village egg and fowl meat production in Africa. World's Poult. Sci. J. 54, 73-85.

Islam, R., Kalita, N. \& Nath, P., 2014. Comparative performance of Vanaraja and Indigenous chicken under backyard system of rearing. J. of Poult. Sci. and Tech. 2, 22-25.

Khan, A., 2008. Indigenous breeds, crossbreds and synthetic hybrids with modified genetic and economic profiles for rural family and small scale poultry farming in India. World's Poult. Sci. J. Sci. 64, 405-415.

Khawaja, T., Khan, S., Mukhtar, N., Ali, M., Ahmed, T. \& Ghafar, A., 2012. Comparative study of growth performance, egg production, egg characteristics and haemato-biochemical parameters of Desi , Fayoumi and Rhode Island Red chicken. J. App. Anim Res. 40, 273-283. Doi:10.1080/09712119.2012.672310

Kuhi, H., Porter, T., López, S., Kebreab, E., Dumas, S., Dijkstra, J. \& France, J., 2010. A review of mathematical functions for the analysis of growth in poultry. World's Poult. Sci. J. 66, 227-240.

Magothe, T., Okeno, T., Muhuyi, W. \& Kahi, A., 2012a. Indigenous chicken production in Kenya: II. Prospects for research and development. World's Poult. Sci. J. 68, 133-144.

Magothe, T., Okeno, T., Muhuyi, W. \& Kahli, A., 2012b. Indigenous chicken production in Kenya: I. Current status. World's Poult. Sci. J. 68, 119-132.

McNamara, D., 2010. Eggs: Unscramble the medical facts (WWW document). Egg Nutr. Council.

Narinc, D., Uckardes, F. \& Aslan, E., 2014. Egg production curve analyses in poultry science. World's Poult. Sci. J. 70, 817-828.

Narinc, D., Karaman, E., Firat, M. \& Aksoy, T., 2010. Comparison of non-linear growth models to describe the growth in Japanese Quail. J. Anim. Vet. Adv. 9, 1961-1966.

Okoro, V., Imoukhome, J., Adewusi, B. \& Oyeka, G., 2005. A comparison of pre and early-laying characteristics of four commercial pullet strains in warm wet climate. Anim. Prod. Res. Adv. 1, 110-114.

Roothaert, R., Ssalongo, S. \& Fulgensio, J., 2011. The Rakai chicken model: an approach that has improved fortunes for Ugandan farmers. Int. J. of Agric. Sust. 9, 222-231. Doi:10.3763/ijas.2010.0563

SAS Institute., 2010. SAS/STAT 9.3 user's guide survey data analysis, Statistical Analysis Software User's Guide. SAS Institute Inc., Cary, NC.

Savegnago, R., Nunes, B., Caetano, S., Ferraudo, A., Schmidt, G., Ledur, M. \& Munari, D., 2011. Comparison of logistic and neural network models to fit to the egg production curve of White Leghorn hens. Poult. Sci. 90, 705-711.

Savegnago, R., Cruz, V., Ramos, S., Caetano, S., Schmidt, G., Ledur, M., El Faro, L. \& Munari, D., 2012. Egg production curve fitting using nonlinear models for selected and nonselected lines of White Leghorn hens. Poult. Sci. 91, 2977-2987.

Selvaggi, M., Laudadio, V., Dario, C. \& Tufarelli, V., 2015. Modelling growth curves in a nondescript Italian chicken breed: An opportunity to improve genetic and feeding strategies. J. of Poult. Sci. 52, 288-294. Doi:10.2141/jpsa.0150048

SPSS, 2007. SPSS Statistics Software 17.0. 978-1-56827-401-0.

Vali, N., 2008. Indigenous chicken production in Iran: a review. Pakistan J. of Bio. Sci. 11, 252-255. 